\title{
Technical Innovation of Ultra-Deep Well Drilling Rig and Its Development Trend
}

\author{
Fang Taian $^{1,2}$, Zhou Zhixiong ${ }^{1,2}$, Wu Changliang, ${ }^{1,}$, *, Yang Xiaoguang ${ }^{1,2}$ \\ ${ }^{1}$ CNPC Engineering Technology R\&D Company Ltd., Beijing, China \\ ${ }^{2}$ National Engineering Laboratory for Oil and Gas Drilling Technology, Beijing, China

\section{Email address:} \\ fangtaiandri@cnpc.com.cn(Fang Taian), zhouzhixiongdri@cnpc.com.cn (Zhou Zhixiong)wuchangliangdr@cnpc.com.cn(Wu Changliang), \\ yangxiaoguangdr@cnpc.com.cn(Yang Xiaoguang) \\ ${ }^{*}$ Corresponding author
}

\section{To cite this article:}

Fang Taian, Zhou Zhixiong, Wu Changliang, Yang Xiaoguang. Technical Innovation of Ultra-Deep Well Drilling Rig and Its Development Trend. International Journal of Oil, Gas and Coal Engineering. Vol. 7, No. 1, 2019, pp. 26-32. doi: 10.11648/j.ogce.20190701.15

Received: December 13, 2018; Accepted: January 3, 2018; Published: January 29, 2019

\begin{abstract}
: 8000-meter drilling rig and quadruple joint 9000-meter drilling rig have been developed for ultra-deep and complex wells of the complicated geological structure area in Tarim Basin, China. The key components of the drilling rigs are redesigned and innovated, including optimization of the high bearing capacity derricks and substructures and a completely new design of integrated single shaft drawworks with the compacted strand wire rope. The rotary table and its driving device with larger torque and load capacity, the high-pressure drilling pump with a high power, intelligent top drive system, casing running device with good compatibility, and automated pipe handling system are equipped. Field application shows that 8000 meters drilling rig, compared with the conventional 9000-meter drilling rig, can save equipment procurement costs by about $20 \%$, reduce drilling operational costs $37 \%$. In addition, the quadruple joint 9000-meter drilling rig can reduce the tripping time by more than $20 \%$, and that the pressure is difficult to control in the complicated formation by conventional drilling rigs can be avoided to a certain extent. At the end of this paper, the advantages and the problems to be solved urgently of the ultra-deep well drilling rigs are expounded.
\end{abstract}

Keywords: Ultra-Deep Drilling Rig, Quadruple Joint, Compacted Strand Wire Rope, Intelligent TDS, Casing Running Device, Automated Pipe Handling System

\section{Introduction}

The geological conditions in the piedmont area of Tarim oilfield are extremely complex, such as thick conglomerate layer, composite salt-gypsum layer, multi-pressure system, high temperature and high pressure alternately appear. The formation can be drilled poorly, the tripping is frequent, the designed well depth in the area is generally over 6000 meters and the weight of casings is generally over $5500 \mathrm{kN}$ due to running multi-layer casings. So the carrying capacity of 7000-meter drilling rig has been unable to meet the requirements of drilling and completion operation. In order to economically exploit the deep reservoirs in the area, Baoji Oilfield Machinery Co. of CNPC developed a $9000 \mathrm{~m}$ ultra-deep drilling rig in 2006. However, the effect is not satisfactory, and it is impossible to achieve the cost cutting and efficiency increasing because of the high daily cost. It is an urgent necessary for ultra-deep well drilling rigs with larger carrying capacity, lower drilling cost and higher cost-effectiveness. Therefore, CNPC organized a joint R\&D team to conduct research on ultra-deep well drilling rigs in 2010, and the first 8000-meter drilling rig in China and the first land 9000-meter quadruple joint drilling rig (hereinafter referred to as quadruple joint drilling rig) in the world for ultra-deep complex wells have been developed in 2012 and 2016 respectively. The key components of the rigs have been redesigned, furthermore, the quadruple joint drilling rig is equipped with a special automated pipe handling system that can significantly reduce the labor intensity during the drilling tool handling, improve the safety and efficiency of drilling operations, and greatly decrease the casualties on the drilling site. 


\section{8000-Meter Ultra-Deep Well Drilling Rig}

A number of independent innovative technologies have been applied to 8000-meter ultra-deep drilling rig. The derrick and substructure of the drilling rig with a maximum load capacity of $5850 \mathrm{kN}$ have been newly designed. The crown block and traveling block with a maximum hook load of $5850 \mathrm{kN}$ have been used on the 8000 -meter drilling rig. The redesigned high-power drawworks has effectively solved the problem of mutual restriction between the lifting capacity of the drawworks and the speed of the hook, which can meet the need of running large tonnage casing in piedmont area of Tarim. The drilling rig is equipped with 52MPa high-pressure mud pumps, and the drilling speed of high-pressure jet drilling is about $40 \%$ higher than that of screw drilling tool combined with PDC bit.

The design of well bore configuration has more choice by using 8000-meter drilling rig. The wellbore spud-in of the casings can be optimized from the fifth spudding to fourth spudding plus tail pipe in a 7000-meter deep well. The size of the tail pipe can increase from $127 \mathrm{~mm}$ of 7000-meter drilling rig to $139.7 \mathrm{~mm}$, and the large size casings above 10 inches can be run to more than 6000 meters, which meets the requirement of the depth for running the large diameter, large tonnage casings and the high-pressure drilling operation in the ultra-deep wells. And the contradiction between insufficient bearing capacity of 7000-meter drilling rig and excessive daily cost of 9000-meter drilling rig in piedmont area of Tarim can be effectively solved as well. Meanwhile, the domestic drilling rig series is enriched [1].

\section{Quadruple Joint Ultra-Deep Well Drilling Rig}

In order to solve the problems in piedmont area of Tarim, such as frequent accidents, often tripping and long drilling cycle, increase drilling speed, reduce drilling accidents, decrease the comprehensive costs, save energy and lower consumption, the first quadruple joint land drilling rig in the world has been developed, which breaks through the technical bottleneck of long quadruple joint and operations in the super-high derrick [2].

The quadruple joint drilling rig is the customized equipment specially designed for complex ultra-deep wells in Kuqa piedmont area. Compared with the conventional triple joint drilling rigs, its tripping speed is obviously increased, the frequency of makeup and breakout is reduced, and the probability of complex downhole accidents caused by the pressure fluctuation of drilling tool pause is lowered. Therefore the drilling efficiency is remarkable. Taking a 7000-meter drill string as an example, it takes about 180 times for tripping by quadruple joint drilling rig, and 66 times less than triple joint drilling rig. So the tripping time and drilling cycle are drastically declined.

\section{Core Supporting Technologies for Ultra-Deep Well Drilling Rig}

The key components of 8000-meter drilling rig and the quadruple joint drilling rigs are redesigned in order to further solve the operation problems of ultra-deep well in the piedmont area of Tarim oilfield, which mainly include the high-bearing capacity derrick and substructure with optimized design, the hoisting system with compacted strand wire rope, the integrated single-axle drawworks with larger rope capacity, the rotary table with greater torque and carrying capacity, the high-pressure mud pump with high-power, the high-power electric control system, the intelligent top drive system, the top drive casing running device with good compatibility, and automated pipe handling system, etc.

\subsection{Ptimized Derrick and Substructure}

(1) All the derricks of the two ultra-deep well drilling rigs are the model $\mathrm{K}$ with open front design connected by padeyes and pins, which is easy for low level dismantling, mounting and sectional transportation. The effective height of the derrick of 8000 -meter drilling rig is 48 meters, which is equivalent to the effective height of the derrick of the 9000-meter conventional drilling rig and meets the arranging requirements of triple joint. The effective height of the derrick of quadruple joint drilling rig is 57.5 meters, which is 9.5 meters higher than that of conventional 9000-meter drilling rig. The derrick is also equipped with an auxiliary racking board to meet the safe arranging requirements of the long quadruple joint and the operation of small-sized dual joints.

(2) The substructure is divided into front and rear platforms, and the front platform is higher than the rear. It is a new type of rotary lifting structure, and the rear platform is used to install drawworks and counterweight water tanks, thus the low level mounting of A-frame, derrick and drawworks can be realized. The lifting load of the substructure of this structure with good overall stability is obviously reduced compared with that with the traditional rotary lift structure. The substructure with a spacious drill floor and a good operational sight plays the role of counterweight and improves the overall stability of the drill rig. The A-frame of quadruple joint drilling rig is lifted by hydraulic cylinders, which is convenient and safe to operate and avoids the risk of overhead working.

(3) Q345D low alloyed steel with good strength, toughness and low-temperature impact resistance is used on the derrick and substructure of 8000-meter drilling rig, while Q420E low alloyed structural steel with higher strength, toughness and low-temperature impact resistance is used for the derrick and substructure of quadruple joint drilling rig. The weight is reduced by more than $10 \%$ compared with that of Q345 used on conventional drilling rigs, and it can meet the working environment requirements of $-35^{\circ} \mathrm{C}$ in winter in Tarim oilfield [3]. They ensure the strength and reduce the lifting load of derrick and substructure as well, which provide the lifting safety performance improvement and working stability of the derrick and substructure. 

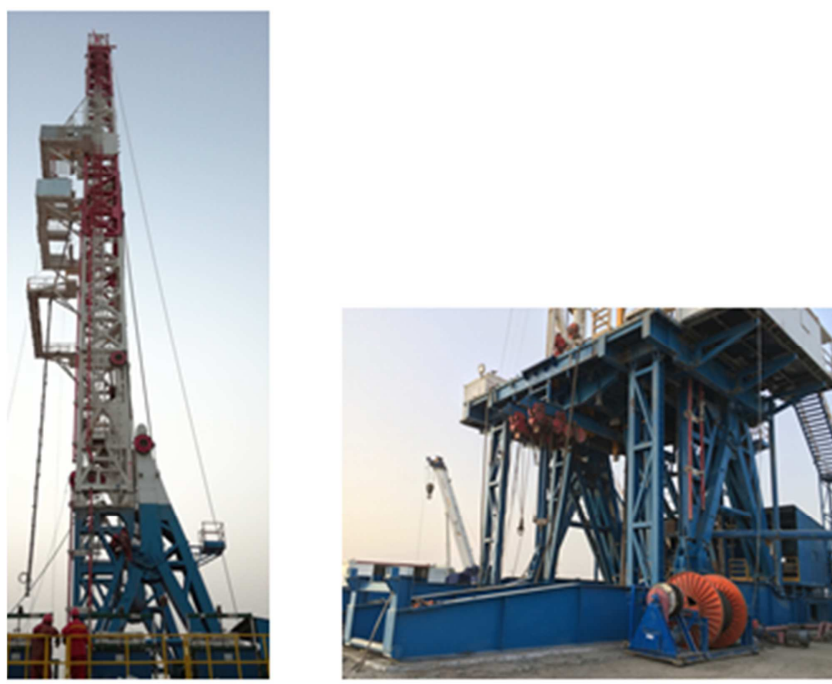

Figure 1. Derrick and Substructure of Quadruple Joint Drilling Rig.

\subsection{New Type Hoisting System}

The new type hoisting system of 8000-meter drilling rig and quadruple joint drilling rig can significantly reduce the tension of fast line, decrease the operational load and power of the drawworks and greatly improvae the safety factor of hoisting drill tools as well [4], there are different levels of optimization and improvement compared with the hoisting system of conventional drilling rig [5].

(1) The drill wire rope system of the crown block and traveling block for 8000 -meter drilling rig is $7 \times 8$, and the compacted strand wire rope with a groove diameter of $38 \mathrm{~mm}$ is used. The carrying capacity of the compacted strand wire rope with high metal density, better abrasion resistance and strong impact resistance is 1.3 times higher than that of uncompressed. It ensures the load requirement of 8000-meter drilling rig and avoids too much increasing in the size and quality of drawworks drum. DG675 hook and SL675 swivel of conventional 9000-meter drilling rig are used on 8000-meter rig to reduce the cost of research and development.

(2) The drill wire rope system of crown block and traveling block for quadruple joint drilling rig is also $7 \times 8$, and the outer diameter of main sheave is $1400 \mathrm{~mm}$ (55 inches)with compacted strand wire rope of diameter $42 \mathrm{~mm}$. It can sustain the hook load of $6750 \mathrm{kN}$, expand the insufficient rope capacity of drawworks and also decrease the quality of the crown block and traveling block as well.

\subsection{Integrated Drawworks}

Drawworks is an important hoisting equipment of drilling rig. It is necessary to consider increasing the rope capacity of drawworks without increasing the size of drawworks as much as possible while satisfying the hoisting capacity of ultra-deep well drilling rig. Therefore, the drawworkses of 8000-meter and quadruple joint drilling rig are newly designed.

(1) The drum body of the drawworks of 8000-meter drilling rig is finished by casting and welding, and its grooves are machined integrally [6]. The winding wire rope capacity of the drawworks drum can be increased by using the compacted strand wire with a diameter of $38 \mathrm{~mm}$, so that the quality and size of the drawworks is not be too large. A method that enlarges wire rope capacity by appropriately increasing the length of the drum is used without changing the diameter of the drawworks drum. All the parts of the drawworks are mounted on one base with the help of new integrated design. The drawworks is easy for integral installation, disassembling and transportation because of its compact design and light weight compared with the 7000-meter DC drive drawworks which main body and the power units are mounted separately [7].

The speed adjustable range is expanded, the lifting capacity is enhanced and the hook speed is improved as well by means of the transmission mode combined with mechanical gear shifting and stepless motor speed regulation for the drawworks. The transmission ratio and torque of the drawworks can run up to the maximum hook load of $5850 \mathrm{kN}$, and the maximum lifting speed of JC-80DB drawworks can reach $1.7 \mathrm{~m} / \mathrm{s}$ at 14 wire rope system. The problem that the hoisting capacity and the hoisting speed of the drawworks mutually restricted can be effectively solved.

(2) The integrated drawworks design concept is also used in the drawworks of quadruple joint drilling rig. The drawworks is divided into three units with high positioning accuracy, which can be transported both wholly and separately. The length of the drawworks drum of the quadruple joint rig is increased from $1840 \mathrm{~mm}$ of the drawworks drum of 9000 -meter conventional drilling rig to $2055 \mathrm{~mm}$, the drawworks has the larger wire rope capacity and the higher strength after using the $7 \times 8$ wire rope system and the $\Phi 42 \mathrm{~mm}$ compacted strand wire rope, furthermore, the working efficiency of the drawworks is obviously improved with the help of a remote pneumatic gear shifting mechanism of the reduction gearbox.

\subsection{Heavy Load Rotary Table and Its Driving Device}

ZP375Z reinforced rotary table is used on both 8000-meter drilling rig and the quadruple joint drilling rig. Its bevel gears have strong abrasion performance after surface strengthening treatment and the base has the greater carrying capacity in virtue of the welding structure with high-strength cast steel [8]. The maximum static load is increased from $5850 \mathrm{kN}$ to $7250 \mathrm{kN}$ and the maximum working torque is raised from $32362 \mathrm{~N} \cdot \mathrm{m}$ to $45000 \mathrm{~N} \cdot \mathrm{m}$ compared with the conventional ZP375 rotary table.

ZP375Z rotary table drive device with the gear reducer and caliper disc brake has higher transmission efficiency and abrasion resistance performance and its caliper disc brake has higher braking moment and response speed compared with the traditional chain reducer and pneumatic tire brake.

\subsection{High-Pressure Mud Pump with High-Power}

F-1600HL or F-2200mud pump with the high-power, large-displacement and high-pressure is equipped in the 8000 -meter drilling rig and the quadruple joint drilling rig, and its rated pressure can reach to $52 \mathrm{MPa}$, which meets the 
requirements of downhole high-pressure tools and bits during the drilling operation in ultra-deep wells, help the bit to break rocks, prolong the service life of the bit and improve the drilling footage as well [9]. F-1600HL mud pump has the following characteristics compared with the conventional F-1600 mud pump.

(1) The diameter range of the cylinder liners of F-1600HL mud pump can be chosen from $120 \mathrm{~mm}$ to $190 \mathrm{~mm}$ and that of F-1600 mud pump is from $140 \mathrm{~mm}$ to $180 \mathrm{~mm}$. The displacement and pressure of F-1600HL mud pump are improved significantly higher than those of F-1600 mud pump. The maximum displacement can be obtained by selecting $\Phi 190 \mathrm{~mm}$ cylinder liner and its supporting plunger, and the rated working pressure of 52MPa can be reached by selecting the cylinder liner of $\Phi 120$ and its supporting high pressure plunger of F-1600HL mud pump.

(2) The power end of F-1600HL mud pump is the same as that of F-1600 mud pump. The working pressure of the hydraulic end of $\mathrm{F}-1600 \mathrm{HL}$ mud pump is redesigned according to the high pressure of $52 \mathrm{MPa}$. The hydraulic cylinder of F-1600 mud pump is an integral one with the suction cylinder and the discharge cylinder as a one-piece, while the hydraulic cylinder of F-1600HL mud pump is the split, that is to say, suction cylinder with an L-shape inner chamber is installed on the discharge cylinder. The displacement and pressure can be selected according to the well conditions, and the hydraulic cylinder is easy to assemble, disassemble and maintenance.

\subsection{Intelligent Top Drive System}

DQ80BSC top drive system is mainly designed for the ultra-deep wells and complicated wells. Its performance has been greatly improved compared with 7000-meter top drive system.

(1) Intelligent control system. The rotating speed and torque control system of the conventional top drive system is manually set and cannot be adjusted with the change of drilling conditions. And the intelligent rotating speed and torque control system of DQ80BSC top drive system can automatically identify the drilling conditions according to the set value of the rotating speed and torque of the top drive system and the actual value returned from the downhole drill string and make real time adjustment to the rotating speed and torque output characteristics of the top drive main spindle to effectively control the drill string is being impacted, twisted off or dropped out due to the sudden change of the downhole torque. The risk of drill string failure and bit wear is greatly reduced and the service life of the drill string and the drill bit is prolonged.

(2) Positioning control technology. Only controlling the rotation speed and torque of the main spindle that means the conventional top drive system merely provides rotary power for the drill pipe, so, the drilling accuracy and efficiency are very low, it is necessary to frequently stopped to adjust the tool face like the conventional rotary drilling [10]. DQ80BSC top drive, by means of the rotary positioning control technology of the main spindle of the top drive system, can precisely control the rotation angle of the top drive main spindle, and it is not necessary to stop drilling when adjusting the azimuth, which can effectively improve the drilling accuracy and efficiency of the directional drilling operation [11].

(3) Sliding control technology. DQ80BSC top drive system with sliding control technology for steering drilling can be used to reduce the friction resistance and the viscous capillary effect between the drill string and the borehole wall in the oriented hole, stabilize the drilling pressure and prolong the service life of the bit by forward and reverse reciprocating swing of the drill string on the basis of not affecting the orientation. Thereby the penetration rate can be improved, and the drilling cycle can be shortened.

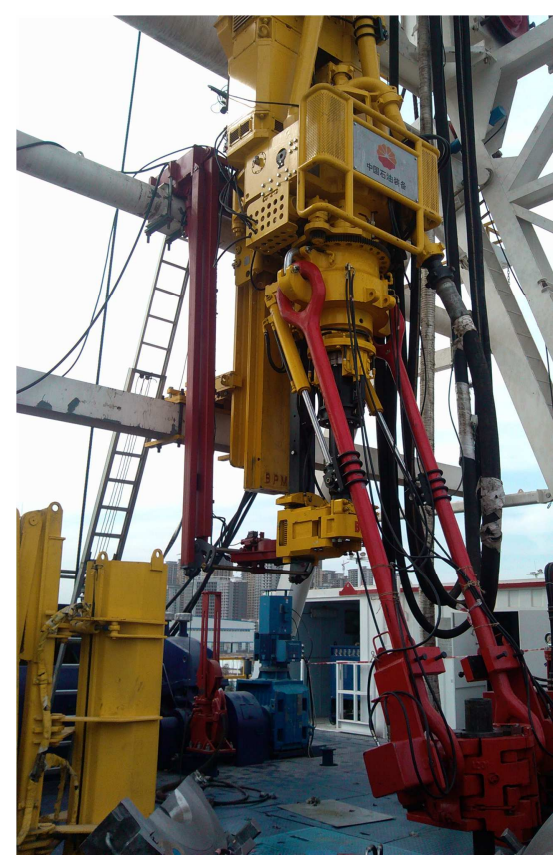

Figure 2. Top Drive System.

\subsection{Casing Running Device of Top Drive}

Casing running device, a new type of device based on top drive drilling system, integrates mechanical and hydraulic technology. The device can replace the casing tong widely used in drilling operations at home and abroad. The rotation of string and the circulation of the drilling fluid can be carried out while the casing is being run due to the application of rotary casing running technology with the top drive system and the casing running device. Thereby the ability of casing to pass through the complex well sections can be improved and casing-running in the deep, ultra-deep, extended reach horizontal wells and the complicated wells will provide a significant support for the safe, efficient and economical drilling.

8000-meter ultra-deep well drilling rig is equipped with casing running system developed by Beijing Petroleum Machinery Co., Ltd. (BPM), including two kinds of casing running devices. One is an external gripping type (see Figure $3 a$ ) for the smaller size casing and the other is an internal gripping type (see Figure $3 b$ ) for the larger size casing. 
Both the internal and external gripping casing running devices

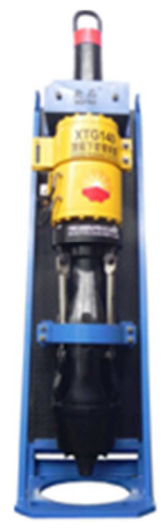

a. extemal gripping type casing running device have covered the casing sizes range from $41 / 2^{\prime \prime}$ to $20 "$.

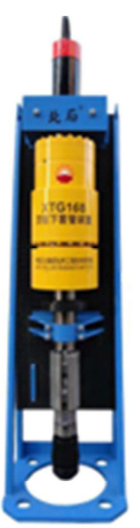

b. intemal gripping type casing running device

Figure 3. Outlines Drawing of Casing Running Devices of BPM.

\subsection{Automated Pipe Handling System}

At present, the automated pipe handling system in China mainly includes hanging, horizontal-to-vertical, push-pull and combined type [12]. The advantage of the hanging automated pipe handling system is that the pipe is not disturbed by other equipment and anywhere it is on the drill floor while working and the automated derrick-hand can flexibly grip the pipe and lay it in the designated place of the racking board according to its own operation mode. However, the derrick will be deformed by the gravity when the lifted string is heavier (such as large diameter drill collar), and it is difficult for the string to operate according to the set track in severe cases. The advantage of horizontal-to-vertical automated pipe handling system is that the equipment, such as the automated pipe arranging rack, power catwalk and drill floor robot, are omitted, but it is only suitable for operation on a single joint drilling rig. The stress of push-pull automated pipe handling system with a compacted mechanical arm is small and can effectively resist the deformation caused by excessive gravity during the string transfer process. But it is necessary to work with the drill floor robot to complete the pipe handling. The combined automated pipe handling system makes full use of the advantages of the suspension and push-pull design, but it is necessary to take different approaches according to different situations, and the operation procedure and process are also slightly complex.

The push-pull automated pipe handling system (as shown in Figure 4) is mounted on the quadruple joint drilling rig after a period of trial operation in the field in order to control the risk on the drill floor and reduce the labor intensity. The system mainly includes power catwalk, power racking board, automated derrick-hand, hydraulic turnover elevator, buffering robotic arm, iron roughneck and drill floor robot, etc. The control system integrated into the driller's room is controlled by the main and assistant drillers.

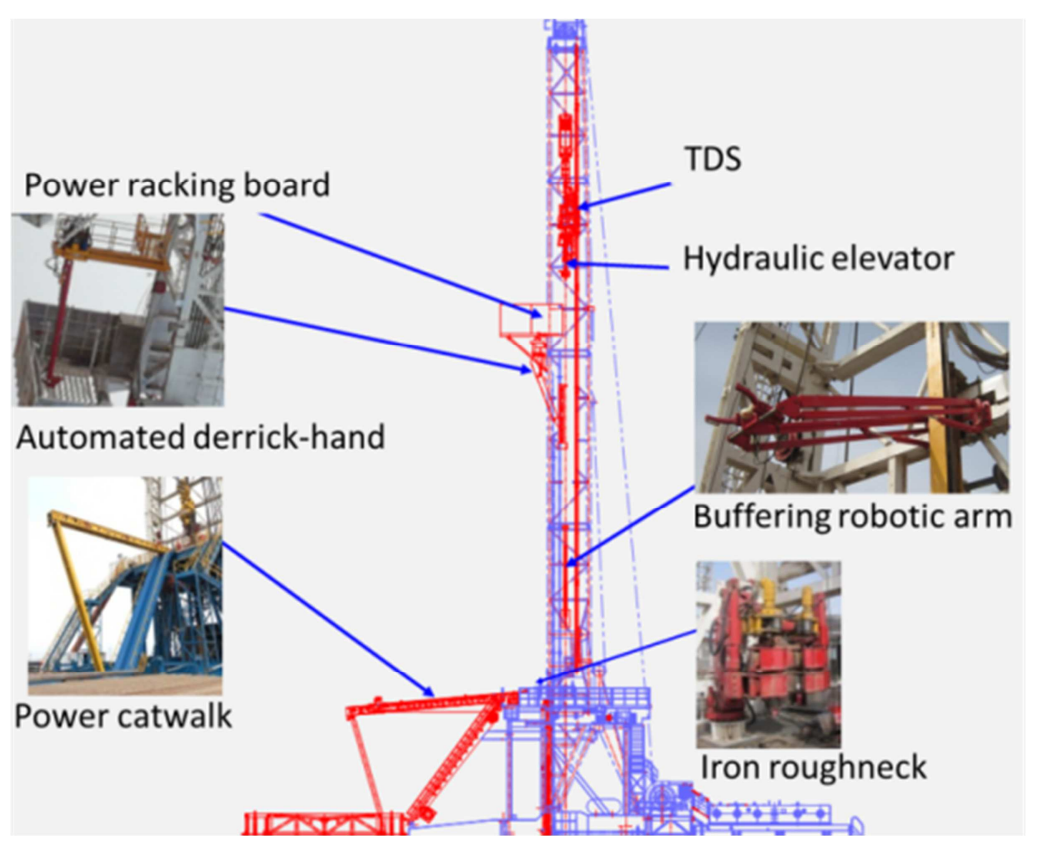

Figure 4. Vertical View of Automated Pipe Handling System. 


\section{Field Applications}

8000-meter drilling rig and the quadruple joint drilling rig are put into trial operation after the successful development. 22 sets of 8000-meter drilling rigs had been successively introduced into Tarim Oilfield Branch of CNPC from 2012 to 2016 and have finished 58 wells. Among which 51 wells had been drilled from 2014 to 2016. Applications show that remarkable effects have been achieved. Meanwhile, industrial applications for the quadruple joint drilling rig to three oil wells in Tarim oilfield had been finished from May 2013 to September 2016.

(1) The equipment cost of 8000-meter drilling rig can be reduced by about one fifth and the drilling cost can be cut down more than $30 \%$ compared with the conventional 9000-meter drilling rig. It has become the preferred drilling rig for ultra-deep wells in Tarim oilfield, and has been applied on a large scale in piedmont area.

(2) The quadruple joint drilling rig has shown remarkable results in improving penetration rate, cutting down drilling time, reducing complex downhole accidents and drilling in conglomerate and salt-gypsum formations. The field application shows that the quadruple rigs have a $20 \%$ reduction in tripping time, less complex conditions encountered during drilling, a $6 \%$ shorten in drilling cycle, and only $2 \%$ outage time for accident, much lower than the average outage time $8 \%$ of adjacent wells in the same area compared with the triple drilling rig. The data of three wells show that the borehole diameter enlargement rate by using the quadruple joint drilling rig has been controlled at a low ratio with only an average borehole diameter enlargement rate of $1.458 \%$ for the whole section, while that of the conventional triple joint drilling rig is $3.8 \%$ and $5.44 \%$ respectively.

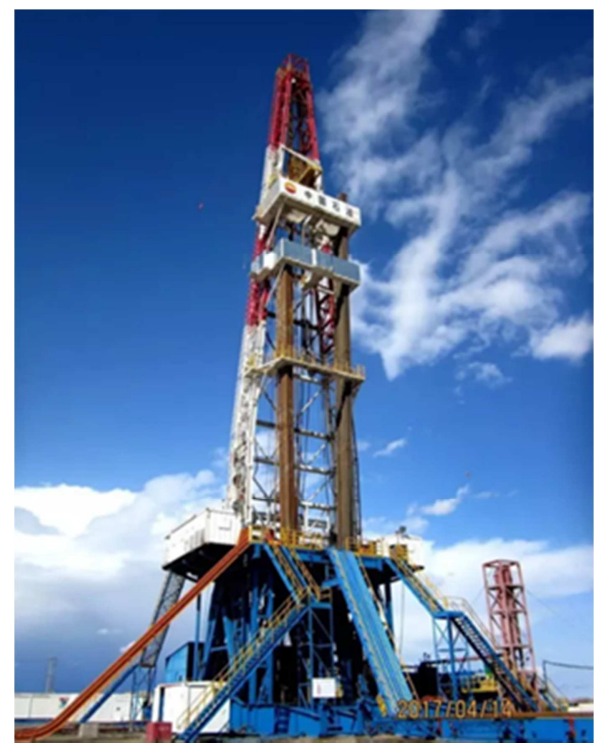

Figure 5. 9000-meter quadruple joint drilling rig at Tarim oilfield.

\section{Conclusions}

Through field application, the following conclusions can be reached.

(1) The equipment cost of 8000-meter drilling rig can be reduced and the drilling cost can be cut down compared with the conventional 9000-meter drilling rig.

(2) The application of quadruple joint drilling rig can improve penetration rate, cut down drilling time, and reduce complex downhole accidents, particularly in conglomerate and salt-gypsum formations.

(3) The application of automated pipe handling system can significantly reduce the labor intensity, improve the safety and efficiency, and greatly decrease the risks on the drilling site.

In recent years, China has intensified its exploration efforts in deep formation. So far, more than 100 ultra-deep wells over 6000 meters have been drilled. With the continuous development in depth and breadth of China's oil industry, whether 8000-meter drilling rig or quadruple joint drilling rig will be the preferred drilling rig for ultra-deep well drilling. Both the speed-up effect and the advantages of reducing downhole accident rate of the quadruple joint drilling technology will be widely used. The development trend of ultra-deep well drilling rig is as follows.

(1) With the gradual maturity of quadruple joint drilling technology, it can be considered for application the technology to an 8000-meter drilling rig. Because the salt-gypsum layer or conglomerate layer, both of which belong to the non-compacted formations, are often drilled in ultra-deep wells, the poor compaction effect of drill bits is easy to lead to well deviation and wellbore diameter enlargement. The quadruple joint drilling rigs have longer continuous movement time in the well, less frequency of makeup and breakout and smaller pressure fluctuation compared with the conventional drilling rigs, so the drilling efficiency in conglomerate layer, gypsum layer and salt-conglomerate interbed has been significantly improved.

(2) The rotary cutting motion of the bit is being performed at the bottom hole during normal drilling, and the bottom hole interfaces present a concave-convex and ordered surface owing to the restriction of the bit shape., The forces exerting on the horizontal direction by each blade of the bit are not uniform when the bit acts on the concave-convex surface again. Some blades have been compacted, and the others are still suspended, which makes the transient change force and torque of the bit more obvious, the cutting teeth of the bit are easier to be crushed or fractured and the early damage of the bit will be more serious. So the more frequent the bit trips, the larger the instantaneous force and torque and the higher the probability of serious damage in advance. Most of the current practice for reducing the damage to the bit is to optimize the bit design and install rotary impact power drilling tools. And the quadruple joint drilling technology that combines the quadruple joint drilling rigs with the top drive system can increase the time of continuous movement of the drill bit at the bottom hole, reduce the tripping frequency, decrease the transient pressure and torque of the bit and lower the probability of drill bit damage in advance, which make the borehole diameter more regular and the controlled well 
trajectory more effective. And this effect was unexpected when designing the quadruple joint drilling rig.

(3) Combining the automated pipe handling system with quadruple joint drilling technology will further improve drilling speed and reduce downhole complex accidents, which is also the future development trend of 8000-meter drilling rigs. However, there are still many shortcomings in the automated pipe handling system currently used on quadruple joint drilling rigs. A lot of major equipment such as the iron roughneck and the drill floor robot are all controlled manually or operated by manual remote control box outside the driller's room. They have not been fully integrated into the driller's room, and there are many potential safety risks. Low visualization will result in many blind spots. It takes longer time for power catwalk to work with hydraulic turnover elevator. The low efficiency of pipe handling system is only comparable to manual operation with the iron roughneck. The thread is easy to be galled while breaking out with the iron roughneck. Once it occurs, only the type B tongs driven by hydraulic cathead can be used.

\section{Acknowledgements}

The authors would like to thank the China National Science and Technology Major Project "Automated Drilling Technology and Equipment for Deep and Ultra-deep Wells" (2016ZX05020-001) for the grant and are also grateful to CNPC Tarim Oilfield Company, Bohai Drilling Engineering Company Ltd., Baoji Oilfield Machinery Co., Ltd and Beijing Petroleum Machinery Co., Ltd. for the support.

\section{References}

[1] Wang Haige, Ge Yunhua, Shi lin. Technologies in Deep and Ultra-Deep Well Drilling: Present Status, Challenges and Future Trend in the 13th Five-Year Plan Period (2016-2020) [J]. NATURAL GAS INDUSTRY, 2017, 37 (4): 1-8.
[2] China's Ultra-Deep Drilling Rig Technology Has Advanced to A New Level. [J]. NATURAL GAS INDUSTRY, 2012, 40 (11): 58 .

[3] Xu Xiaopeng, Huang Yuehua, Li Zhiping, etc. Application of High Strength Materials in Derrick Substructure of Ultra-Deep Well Drilling Rig [J]. PETROLEUM MACHINERY, 2009, 37 (8): $72-75$.

[4] Chen Qing. The Drilling and hoisting system of CNPC Baoji Oilfield Machinery Co., ltd achieve full series coverage [N]. CHINA PETROCHEMICAL NEWS, 2010-01-28.

[5] Huang Xianpu, Dang yuan, Gao Feng. YG-135 type integral traveling car hook design [J]. OIL FIELD EQUIPMENT, 1996, 25 (5): 11-16.

[6] Yang Yuandong, Ma Shuxue, An Qinglong, et al. The Development and Application of the JC-15D Direct Drive Drawworks [J]. PETROLEUM MACHINERY, 2012, 40 (4): 34-37.

[7] Zhang Xiaojie, Dong Hui, Jin Lumin, etc. [J]. Design And Analysis of $8000 \mathrm{~m}$ DC Rigs Drawworks[J]. OIL FIELD EQUIPMENT, 2013, 42 (10): 57-60.

[8] Yang Honggang, Zhou Yafang, Lu Yunhao, et al. Development and Application of ZP495 Rotary Table [J]. PETROLEUM MACHINERY, 2009, 37 (6): 45-47, 95.

[9] Yi Zhou, Zhiqiang Huang, Yan Bu, etc. Simulation Studies on Drilling Mud Pump Plunger Seal Failure under Ultrahigh Pressure and Ultra-deep Conditions [J]. ENGINEERING FAILURE ANALYSIS, 2014.07.005, 2014, 45 (10):142-150.

[10] Chen Ruheng. Breaking-up Old Concept, Creating New Drilling Rigs (Part 3) [J]. OIL FIELD MACHINERY, 2008, 37 (5): 1-9.

[11] Xu Wen, Liu Xinli, Ma Rui, et al. Top Drive-based Steering Control Technology for Slide Drilling [J]. PETROLEUM MACHINERY, 2013, 41 (3): 27-30.

[12] Wang Dingya, Wang Yaohua, Yu Xingjun. Research and Development Trend of Domestic Automated Drilling Rig [J]. PETROLEUM MACHINERY, 2017, 45 (5): 23-27. 